\title{
“¡Desperta Polska!” de Eduardo Pondal no contexto da loita independentista polaca
}

\author{
“'Desperta Polska!” by Eduardo Pondal in the Context of the \\ Polish Struggle for Independence
}

\author{
Maria Boguszewicz \\ Universidad de Varsovia \\ Instituto de Estudios Ibéricos e Iberoamericanos \\ m.boguszewicz@uw.edu.pl
}

[recibido 31/10/2014, aceptado 26/01/2015]

\section{RESUMO}

Ao final da súa vida, Eduardo Pondal escribiu o poema titulado “¡Desperta Polska!” dedicado á loita independentista deste país que, a consecuencia das tres particións de finais do século XVIII, desapareceu do mapa. O obxectivo deste artigo é situar o poema no seu contexto histórico tanto polaco coma galego grazas ao que obteremos unha reflexión aprofundada sobre a visión pondaliana de Galicia e o seu papel na historia.

Palabras Chave: Eduardo Pondal, Galicia, Polonia, “¡Desperta Polska!”, Rexurdimento.

\section{RESUMEN}

Al final de su vida, Eduardo Pondal escribió el poema titulado “¡Desperta Polska!” dedicado a la lucha independentista de este país que, a consecuencia de las tres particiones de finales del siglo XVIII, desapareció del mapa. El objetivo de este artículo es situar el poema en su contexto histórico tanto polaco como gallego gracias a lo cual obtendremos una reflexión profundizada sobre la visión pondaliana de Galicia y su papel en la historia.

Palabras Clave: Eduardo Pondal, Galicia, Polonia, “¡Desperta Polska!”, Rexurdimento.

\begin{abstract}
In the later years of his life, Eduardo Pondal wrote a poem entitled “¡Desperta Polska!”. This poem was dedicated to the struggle for independence in this country which was at the time divided between the three different partitions from the late eighteenth century and later disappeared from the map. The aim of this article is to place the poem in its historical context (Polish and Galician) thanks to which we will obtain further reflection on the vision that Pondal had about Galicia and its role in history.
\end{abstract}

KEY wORDS: Eduardo Pondal, Galicia, Poland, “¡Desperta Polska!”, Rexurdimento.

Boguszewicz, M. (2015): “«iDesperta Polska!» de Eduardo Pondal no contexto da loita independentista polaca”, Madrygal (Madr.), 18, Núm. Especial: 257-266.

SUMARIO: 1 . Introdución. 2. Anarquía, intolerancia e barbaridade. 3. Polonia inxusta, nobreza maldita. 4. Polonia no espello galego. 5. Galicia no espello polaco. 6. Conclusións. 7. Referencias bibliográficas. 


\section{INTROUDUCIÓN}

Eduardo Pondal escribiu "¡Desperta Polska!", segundo a datación de Manuel Ferreiro, entre 1900 e 1910 (Ferreiro 2002: XVII-XVIII). Non chegou a publicalo e legouno xunto cos outros poemas manuscritos á Real Academia Galega. Recentemente, Manuel Ferreiro editou estes poemas no tomo III da "Poesía Galega Completa" de Eduardo Pondal (Pondal 2002).

A xénese deste poema do vate galego non parece ser un grande misterio. Polonia daquela xa se convertera nun símbolo da loita independentista, dun país oprimido, que desesperadamente buscaba a súa liberdade por todos os medios. Sería, pois, un símbolo romántico, un Mesías das nacións, como quería velo Adam Mickiewicz ${ }^{1}$.

Por outra banda, cómpre ter presente a Rusia de principios do século XX. Trátase dunha Rusia debilitada tanto pola crise económica como pola guerra co Xapón. Namentres, o proletariado, grazas ao intenso desenvolvemento industrial do século XIX, xa era unha clase social capaz de formular politicamente os seus postulados agrupándose en partidos e organizando folgas. Deixadas de lado e desdeñadas polo zar, as clases baixas facían tremer o seu imperio.

Non hai, pois, moito sentido en preguntarse por que Pondal escribiu este poema ou por que escolleu este país -aínda que non de modo exclusivo- para expresar o seu apoio. O que si parece ser digno de reflexión é o problema do significado de tal escolla. É dicir, desde o punto de vista polaco é interesante ver que elementos da súa historia forman parte desta mitoloxía romántica polaca e como se plasman neste caso en concreto. En troca, desde a perspectiva galega pode resultar proveitoso preguntarse por que precisamente estes elementos lle pareceron operativos a Pondal.

\section{ANARQUÍA, INTOLERANCIA E BAR- BARIDADE}

Polonia como un punto de referencia no mapa de Europa apareceu no século XIV, cando, despois dun período da división territorial entre varios ducados, o rei Władysław Łokietek (Ladislao) conseguiu reunificar o reino. A finais dese mesmo século, chegou a dominar políticamente no país a nobreza, que nos séculos seguintes ía desempeñar un papel decisivo na historia de Polonia.

O apoxeo da potencia de Polonia comezou despois da Unión de Lublin (1569), cando a Coroa de Polonia se uniu co Grande Ducado de Lituania. A República das Dúas Nacións (Rzeczpospolita Obojga Narodów) converteuse nun Estado dominante en Europa Central, próspero economicamente e, canto á superficie, un dos máis grandes no continente. Ao mesmo tempo, a nobreza tomou en posesión o reino introducindo un sistema único que se apoiaba no poder desta clase social e se denominaba a "democracia dos nobres". Eran, pois, os mesmos nobres os que decidían os gobernos do país e escollían o seu rei. Até a metade do século XVII, Polonia mantivo a súa posición influente na área internacional, mais as loitas cos veciños, o levantamento dos cosacos, así como a crise económica provocada en grande medida pola falta de reformas necesarias das que non estaban interesados os nobres fixeron depender o país das potencias foráneas.

Mentres que a Coroa se sumerxía cada vez máis na anarquía causada pola defensa a todo custo das "liberdades dos nobres" e perdía o que lle restaba de imaxe civilizada co Tumulto de Toruń gañando a fama de intolerante e bárbara na Europa occidental, os seus veciños (Rusia especialmente) inmiscíanse con crecente enerxía e eficacia nos asuntos internos de Polonia. Os aliados lituanos emprendían os sucesivos intentos de librarse da nación irmá,

\footnotetext{
${ }^{1}$ Andrzej Walicki, especialista no romanticismo polaco, dixo nunha entrevista: "Na miña opinión, el [Adam Mickiewicz] é a figura paradigmática do mesianismo na escala europea" (Walicki 2006-2007: 31). Tradución da autora ("Moim zdaniem jest on [Adam Mickiewicz] paradygmatyczną figurą mesjanizmu w skali ogólnoeuropejskiej”).
} 
cando en Ucrania estalaban numerosas rebelións contra a dominación polaca. Finalmente, no ano 1772, Rusia, Austria e Prusia repartiron entre elas o $30 \%$ do territorio de Polonia. En 1793 produciuse a segunda e en 1795 a terceira partición que concluíu coa desaparición deste Estado do mapa.

Entre a primeira partición de Polonia e a súa liberación despois da I Guerra Mundial, tiveron lugar varios intentos (todos fanados desde logo), de maior ou menor alcance, de independización do país mediante a loita armada. A primeira tentativa aconteceu pouco despois da segunda partición, en 1794, e foi liderada por Tadeusz Kościuszko. Polonia tamén participou na Primavera das Nacións en 1846. Porén, as insurreccións máis importantes foron as de 1830-31 (Levantamento de Novembro) e de 1863 (Levantamento de Xaneiro). Aínda que os polacos emigraran xa antes, desde a primeira invasión dos países veciños, estas dúas insurreccións iniciaron a grande emigración cara á Francia na que abandonaron a patria importantes sectores da sociedade polaca como intelectuais, artistas e escritores. Deste xeito formouse en París un centro importante da cultura e política polacas. Desde alí as noticias sobre Polonia e o impacto da súa cultura expandíronse aos países circundantes, entre eles a España.

Polonia, desde a época romántica cando a cantaron os grandes vates polacos como Słowacki o Mickiewicz, convertérase nun mito da loita desesperada pola liberdade. Murguía (1975: 141) nos "Precursores", no capítulo dedicado a Pondal, menciona a Mickiewicz, o grande poeta romántico que fixo de Polonia o Mesías das nacións. Otero Pedrayo, nos "Camiños da vida", botou man da asociación con este país cunha intención parecida á de "¡Desperta Polska!", xa que Potocky representaba os valores propios da súa patria (Fernández
Pérez-Sanjulián 2009: 143). Polonia como referente mantívose durante moito tempo ${ }^{2}$ e non só na literatura. O diputado Melquíades Álvarez, fundador do Partido Reformista, afirmou nun debate no Congreso dos Diputados en 1916: “¡Perseguir el idioma [catalán]! ¡Hablar de que el Gobierno español puede hacer con el catalán lo que hace el imperio alemán con el polaco en el distrito de Possen! Temeridad, absurdo"3 (1916: 1015).

Alén da carga simbólica que implica a idea dun imperio caído e esgazado entre os seus veciños, competidores de antano, tamén -como algúns me sinalaron ${ }^{4}$ - a mesma palabra ten $\mathrm{o}$ seu atractivo fonético para os hispanofalantes. De aí que talvez Pondal empregue no poema a versión orixinal do seu nome, "Polska", en vez do seu equivalente galego e castelán, "Polonia". Dunha forma parecida, Pondal decídese polo nome de Cernagora en vez de Montenegro.

\section{POLONIA INXUSTA, NOBREZA MAL- DITA}

Por moito que o quixese aparentar a República Popular de Polonia, Estado satélite da Unión Soviética despois da II Guerra Mundial, este país non é nin nunca foi homoxéneo do punto de vista étnico. Sen falar dos xudeus que constituían nalgún momento a minoría máis numerosa desta nacionalidade en Europa, Polonia compúñase de varios grupos étnicos que mantiñan a súa identidade diferente, as súas tradicións, cultura e nalgúns casos até a lingua.

$\mathrm{Na}$ actualidade, hai só un grupo étnico que non sexa minoría nacional doutro Estado que é recoñecido como tal en Polonia e goza duns dereitos especiais que protexen e fomentan a súa lingua e cultura. Trátase dos casubios, que ocupan parte dos territorios do Norte de

\footnotetext{
${ }^{2}$ Por exemplo, este fragmento do "Tema del traidor y del héroe" de Borges: "La acción transcurre en un país oprimido y tenaz: Polonia, Irlanda, la república de Venecia, algún estado sudamericano o balcánico...” (1944).

${ }^{3}$ Agradézolle a Alfons Gregori esta referencia.

${ }^{4}$ Entre eles Facundo Reyna Muniain.
} 
Polonia coa capital en Gdańsk (Danzig en alemán). A súa fala recoñécese como lingua propia, diferente do polaco e está declarada lingua cooficial no seu territorio. Pódese ensinar na escola, pódese empregar na administración pública, os municipios poden botar man da toponimia bilingüe. Aínda que non existe a obligatoriedade neste sentido nin un soporte económico que potencie estes dereitos, a situación dos casubios está polo menos regulada pola lei. Algo que non acontece cos silesianos que declararon a identidade silesiana dun xeito moito máis masivo que os casubios no último censo ${ }^{5}$.

Porén, aínda que na actualidade os silesianos son talvez máis activos e seguramente máis radicais nas súas reivindicacións políticas, no século XIX foron os casubios os que fixeron florecer a súa cultura, dándolle a forma literaria ao tempo que formularon un proxecto político que mellor reflectise a súa identidade nun contexto histórico complicado.

O pai do movemento rexional casubio foi Florian Ceynowa, quen comezou a súa actividade máis ou menos paralelamente ao Rexurdimento galego. Os seus primeiros escritos referidos aos casubios e na lingua casubia apareceron nos anos 60 do século XIX. Para ser rigurosos cos feitos, hai que recoñecer que nin Ceynowa nin as súas publicacións tiveron realmente unha acollida masiva e positiva na Casubia. Aínda que é verdade que o mesmo Ceynowa publicou até en Rusia, Alemania ou en Chequia, os seus traballos non tiveron un grande impacto nin foron amplamente recoñecidos.

Sobre os casubios escribíase de vez en cando nos países veciños. Na segunda metade do século XIX veu á Casubia Aleksander Hilferding, un etnógrafo ruso, para elaborar unha monografía sobre esta rexión. Durante algún tempo acompañoulle Ceynowa en persoa. A obra que froito desta viaxe constitúe hoxe en día unha fonte histórica moi importante sobre a Casubia decimonónica. Tamén escribían sobre os casubios os alemáns, pastores sobre todo (Lorek, Seidel, Tetzner), os cales pola súa misión ${ }^{6}$ tiñan contacto coa poboación que permanecía baixo a dominación alemá desde a primeira partición de Polonia. As súas descripcións son moito menos entusiastas das de Hilferding, mais achegan informacións valiosas sobre a conflitividade da sociedade casubia-alemá.

Foi precisamente a crecente inimizade das autoridades alemás a que convenceu os primeiros ideólogos do movemento nacional casubio de que a alianza con Polonia sería menos prexudicial para a súa causa que a permanencia no Estado prusiano. Porén, este último era máis atractivo do punto de vista económico, xa que levara a cabo as reformas das que a nobreza polaca non quixera nin escoitar no seu tempo. Porén, levaba a cabo unha política cultural que non era aceptábel para a nova élite casubia (cuxa aparición foi posíbel precisamente grazas a estas reformas). O culturcampf prusiano, dirixido principalmente contra os polacos, tamén lles afectaba aos casubios. Entendendo que se trataba de ser ou non ser da nación casubia como unha entidade diferenciada, coa súa cultura e lingua, os líderes do rexionalismo decidiron xuntarse ao movemento independentista polaco baixo a consigna do paneslavismo.

A escolla non foi nin evidente nin fácil. Daquela os casubios non se identificaban con Polonia; tampouco cos alemás. Os casubios sentíanse casubios e así se definían. Eran diferentes dos alemáns dun modo absolutamente evidente e dos polacos lingüística e culturalmente. O que compartían con estes últimos era a relixón e este precisamente era o vínculo decisivo. A ameaza que constituía para a súa confesión católica a política prusiana, non lles deixou moita elección aos casubios e fíxoos leais a Polonia.

\footnotetext{
${ }^{5} 809$ mil declaracións silesianas fronte 228 mil casubias. Das primeiras até 362 mil eran da identidade única (non dobre polaco-silesiana), mentres que no caso casubio foron só 16 mil (GUS 2012: 17-18).

${ }^{6}$ Porén, lémbrese que os casubios eran católicos.
} 
Porén, no pasado, estes vínculos non eran nada fortes. En 1911, Jan Karnowski, un dos líderes do movemento casubio, describía así a situación na Casubia no século XIX:

O pobo casubio durante moito tempo, porque até a metade do século pasado non era polaco, non tiña a poloneidade na alma. O que conservou do pasado da Polonia antiga foi a relixión católica e a lingua polaca na igrexa. Alén diso sabe só que existiu a Polonia grande, a Polonia fidalga, a Polonia inxusta ${ }^{7}$. (ObrachtProndzyński 2003: 175)

A cultura casubia pasou por un proceso parecido ao caso galego e sufriu unha degradación social chegando a ser propia das clases baixas. As elites autóctonas ou foron desprazadas ou poloneizáronse. Xa o mencionado etnógrafo ruso, Hilferding, apuntaba no seu libro como a nobreza desdeñaba os plebeos casubios converténdoos en inimigos:

Polonia, que durante tantos séculos reinaba en Pomerania, podía facilmente construír a irmandade con el [o pobo casubio]. Non o fixo polo eterno desprezo que sentía cara ao pobo baixo. Os casubios son uns campesiños primitivos, a súa lingua é o dialecto feo do polaco; como os grandes señores se ían ocupar do pobo baixo e da súa lingua primitiva? Esta é a opinión dos polacos-herdeiros que conservaron aínda parte das súas terras en Casubia. $\mathrm{Na}$ conversa comigo chegaban a rirse de que me interesase polos casubios e a súa lingua. (...) O clero católico neste país (...) oponse á xermanización. Porén, desgraciadamente, os máis dos seus representantes senten o mesmo orgullo aristocrático ante os casubios e o seu dialecto ${ }^{8}$. (1989: 21).

Ceynowa escribía, desde a cadea9: "É verdade que a nobreza está maldita así como a súa prole non lle desexa a felicidade a ningún home, e menos ao casubio, e por iso constantemente o incomoda"10 (2004: 78).

Cando finalmente Polonia recuperou a independencia despois da I Guerra Mundial, os casubios foron tratados na II República Polaca como cidadáns de segunda categoría. O Estado desconfiaba deles pola súa identidade diferente e tachábanos de alemáns. A situación empeorou aínda despois da II Guerra Mundial, e iso malia os casubios perderan nesta ocasión a maior parte da súa intelectualidade executada polos nazis. A República Popular Polaca xa non desconfiaba da identidade propia dos casubios, senón simplemente negábaa ${ }^{11}$ perseguindo calquera das súas manifestacións.

${ }^{7}$ Tradución da autora: "Ludność kaszubska długo, bo aż do drugiej połowy ubiegłego stulecia polską nie była. Polskości w duszy nie miała. Co jedynie z przeszłości starej Polski zachowała, to jest ową wiarę katolicką i język polski kościelny. Pozatem wie tylko, że istniała wielka Polska, Polska szlachecka, Polska niesprawiedliwa".

${ }^{8}$ Tradución da autora: "Władająca tyle wieków Pomorzem Polska łatwo mogłaby zadzierzgnąc między nim [ludem kaszubskim] a sobą ścisłe nici pokrewieństwa. Nie zrobiła tego wskutek wiecznej swej pogardy wobec prostego ludu. Kaszubi to zwykli prości włościanie, chłopi; mowa kaszubska to zepsute narzecze pospólstwa; jakżeby wielmożni panowie mogli zajmować się nisko urodzonym prostym ludem i jego prostacką mową? Tak oto uważają do tej pory Polacy-dziedzice, którzy zachowali jeszcze część swych majątków w kraju kaszubskim. W rozmowie ze mną wyrażali nawet na wpół kpiące zdumienie, że Kaszubów i mowę kaszubską znajdywałem godnymi badania naukowego. (...) Duchowieństwo katolickie w tym kraju (...) nie sprzyja rozpowszechnianiu się żywiołu niemieckiego. Ale, niestety, większość jego przedstawicieli, tak samo, jak szlachta, owładnięta jest duchem polskiej, arystokratycznej dumy w stosunku do Kaszubów i ich narzecza".

${ }^{9}$ Pola súa actividade na Primaveira dos Pobos.

${ }^{10}$ Tradución da autora: "To prawda, ze szlach jest przeklęty jak i jego potomstwo, szlachta nie życzy człowiekowi szczęścia i dlatego mu nieustannie dokucza, osobliwie Kaszubie".

${ }^{11}$ Nunha das instrucións internas do Partido Obreiro Unificado Polaco (Polska Zjednoczona Partia Robotnicza) recomendábase evitar a palabra "casubio", substituíndoa por expresións de tipo descritivo como “a poboación local” (Synak 1998: 140). 


\section{POLONIA NO ESPELLO GALEGO}

No poema “¡Desperta Polska!” é Galicia, identificada coa Cincenta, a que chama a Polonia a espertar. Cando Pondal se refire a este país, evoca os personaxes significativos da historia e vida cultural de Polonia. É un recurso característico deste poeta. Cando fala de historia, especialmente da historia recente, adoita referirse a uns personaxes concretos que simbolizan uns valores determinados. Do mesmo modo, en “¡Desperta Polska!” aparecen os nomes dos reis, como Poniatowski (Poniatouski) e Władysław (Ladislao), dos heroes das loitas independentistas, como Kościuszko (Kosciusko) e Sowiński (Soviewski), e do escritor Sienkiewicz (Sienkiewich). Non son nada casuais estes nomes, xa que cada un deles implica unha carga simbólica considerábel.

O rei Władysław Łokietek (Ladislao) foi o que chegou a reunificar as terras de Polonia dispersas polas herdanzas e o que iniciou o período de esplendor deste reino. O outro rei mencionado, Stanisław August Poniatowski (Poniatouski), foi o último rei da República das Dúas Nacións. Tadeusz Kościuszko (Kosciusko) liderou o primeiro levantamento contra os invasores, a insurrección que leva o seu nome, e ocorreu en 1794. En troca, Józef Sowiński (Soviewski) foi o xeneral que destacou no Levantamento de Novembro de 1831. A súa heroica defensa dun dos barrios de Varsovia así como a súa morte, da que circulaban lendas por non ser aclarada do todo, foron obxecto de varias referencias poéticas e narrativas. E finalmente Henryk Sienkiewicz (Sienkiewich), o Nobel polaco de literatura de 1905, autor das novelas históricas que escribía, como el mesmo explicaba, para animar os polacos á loita sen perder a esperanza.

Desta modo, os principais valores cos que Pondal identifica Polonia son o seu carácter hexemónico, o don de liderado e a forza, así como o seu espírito independente, a natureza belixerante e guerrilleira, a incapacidade inherente de se subxugar. Chama pois a esta Walkiria, como denomina a Polonia, que se rebele contra a besta rusa. Aínda que hai tres Estados ocupantes, é Rusia a que representa o mal dos males, que é cualificada como "besta apocalíptica" (Pondal 2002: 139) e "dura loba" (Pondal 2002: 139). Foi este imperio, precisamente, o que máis influíu na derrota do seu veciño e mais se beneficiou coa súa caída. Mais sobre todo trátabase entón da Rusia zarista, gobernada polo monarca absoluto e intransixente ás necesidades e sufrimentos dos seus súbditos, que ao final lle arrebataron o poder. Rusia, pois, "sangra por todas partes" (Pondal 2002: 139) e treme nos seus fundamentos perdendo coroas e cabezas. E esta Rusia representa para Pondal o despotismo e imperialismo. Así pois, Polonia demostra non só os valores propios, senón que ademais simboliza a outra cara do imperio zarista. É Polonia, así, o único país que é capaz de desafiar esta besta apocalíptica, e non pola súa forza real, pola potencia militar, económica ou política, senón precisamente por esta forza de espírito, a pesar de todo, malia toda as súas derrotas, pese a desigualdade do potencial; a pesar de non existir.

Se analizarmos devagar a historia de Polonia, vemos que o seu mito só parcialmente se corresponde coa realidade. Cousa propia dos mitos, certo. Porén, paga a pena deterse por un momento nos aspectos menos expostos no trance da mitificación romántica.

A época do maior esplendor deste Estado recae no período da República das Dúas Nacións, aínda que o desenvolvemento intenso comezara xa con anterioridade. Polonia incorporou daquela as terras lituanas no seu territorio mediante a unión real (a persoal xa existira con anterioridade entre Polonia e Lituania). Foi unha alianza rexeitada polos mesmos lituanos desde a súa concepción e aceptada finalmente a contragusto. O imperio polacolituano chegou a se converter en hexemónico na súa rexión xeopolítica, sometendo varios pobos e gañando constantemente guerras nas terras fronteirizas. Se acrecentarmos a iso as nacións sen estado, como os casubios, a República das Dúas Nacións era unha área de tensións e conflitos moi importantes no nivel étnico, político e tamén, por suposto, social.

Os valores cos que se asocia a Polonia deste período, a democracia e a liberdade, foron desde o principio propias dunha clase social, a nobreza. Creados e mantidos para protexer os 
seus propios intereses, convertéronse na causa primeira do desastre de toda a sociedade, que tivo que sufrir as consecuencias do egoísmo e indolencia das súas clases acomodadas.

\section{GALICIA NO ESPELLO POLACO}

Eduardo Pondal non é só un dos maiores representantes do Rexurdimento. Despois da morte de Curros Enríquez e de Rosalía de Castro pasou a ser unha figura simbólica das letras galegas (Ferreiro 2007: 13). O autor do himno nacional galego non se declaraba separatista, senón rexionalista (ibid. 48). Este rexionalismo pondaliano, certamente, hai que entendelo na perspectiva iberista (ibid. 47), o que leva a Cores Trasmonte denominar ao poeta "el único nacionalista auténtico de nuestros artistas de la palabra" (1957: 13). Así, en contra da frecuente tendencia nos movementos de liberación nacional de apoloxizar o desastre, como sinala Queizán (1986: 56), Pondal ofrécelles aos galegos a contraideoloxía, a da loita. O celtismo pondaliano desempeña unha función importantísima neste sentido. Por un lado temos a súa historia mitolóxica cos seus heroes, as guerras, a hexemonía e a liñaxe nobre que impregna Galicia do seu prestixio e elitismo. Doutra parte está a herdada natureza salvaxe, a forza da barbarie, o mundo precultural e o antónimo da civilización (Lama López 2001: 117). Será, pois, esta Galicia dobremente predestinada ao liderado na súa vecindade. A pesar de todas as aparencias, da súa lamentábel situación actual, da súa debilidade real, pola forza do espírito guerrillero que aínda latexa nela e polo seu pasado glorioso cantado polo bardo para lembralo á nación durmida.

É máis aínda, Galicia, polas súas características excepcionais, ten que se responsabilizar dos outros pobos. Esta nación debe liderar a loita contra o despotismo e o imperialismo castelán ou calquera outro, contra a decadencia, corrupción e o atraso da Iberia e Lusitania. Porque aínda que se trata da hexemonía, é un concepto altamente positivo na perspectiva pondaliana. Trátase, pois, nas palabras de Cores Trasmonte (1957: 14), do mesianismo hexemónico que se basea na idea do transpersonalismo voluntario. A comunidade, que normalmente esixe a colaboración dos individuos, aquí é máis ben o efecto da libre vontade dos seus membros.

Frente al separatismo egoísta, de hermetismo político, la tesis de Pondal tiene la gallardía de la comunidad inter-grupal, internacional, es decir, de relación comunitaria y afectiva con otros grupos similares, si bien, naturalmente, bajo la enseña y el patrocinio de la cultura celta, galaica, la cultura perfecta a la que hay que imitar, según el criterio del poeta. (Cores Trasmonte 1957: 14)

Como consecuencia, érguese unha Galicia ideal, heroica e estilizada, como a caracteriza Méndez Ferrín (1990: 26). Uns trazos que moi ben podemos aplicar á Polonia pondaliana. A lectura de “¡Desperta Polska!” esperta inevitabelmente as asociacións coa paisaxe da Galicia poboada polos guerrilleros celtas. No escenario da "pranura longa", "estepa" e "deserto", o poeta recrea a "inmarcesibre gloria" e a "generosa loita" (Pondal 2002: 139) dos antepasados que obrigan á nación polaca a aprestar as armas de novo.

Aínda que Galicia fica identificada coa Cincenta na primeira estrofa, non hai que deixarse levar polas aparencias. Non se trata dunha Cincenta pasiva, dun símbolo da mansedume e sumisión. A Cincenta de " $¡ D e s p e r t a$ Polska!" é símbolo de bondade, mais dunha bondade concibida de modo diferente ao que acostuman os contos de fadas. Esta rapaza é "filla dos celtas boa" que "garda de Santiago/ a milagrosa tomba" e "afugentou d'España/ a dura xente moura" (Pondal 2002: 138). O que recolle Pondal do conto clásico é precisamente a capacidade de acción desta personaxe, que chegou a mudar radicalmente a súa situación. Daquela a bondade da Cincenta no poema de Pondal sería esta xenerosidade á que se refire Cores Trasmonte (1956: 17) cando explica o papel de Galicia entre outras nacións na perspectiva pondaliana. Esta filla dos celtas que chama os outros pobos a se xuntar, reparte xenerosamente as súas cualidades excepcionais.

A referencia a Polonia no poema de Pondal ten, por tanto, dúas caras. No primeiro nivel, estabelécese a identificación con esta nación que foi obxecto de mitificación na época 
romántica. Neste sentido ten unha función parecida á do propio mito celta: o afán elitista de Pondal. O poeta sitúa Galicia e Polonia no mesmo espazo polos idénticos valores que ambas representan para el. Quere que Galicia sexa percibida do mesmo modo que un potente Estado hexémonico no seu tempo, tanto dentro como fóra das súas fronteiras. E, ao mesmo tempo, entende que os Estados teñen os seus destinos, que dunha época de esplendor e prosperidade pódese caer noutra de decadencia e até desaparición do mapa. Porén, aínda que no efecto final obtemos un sentimento de solidariedade, non se trata da solidariedade no sufrimento e resignación. Xa nolo indica na primeira estrofa a Cincenta. Se Pondal require a solidariedade, sería a solidariedade na loita, nas armas, no espírito insumiso.

A "voz estrepitosa" (Pondal 2002: 138) que chama desde lonxe, "¡Desperta Polska!”, parece sinalar moito máis dunha simple equivalencia entre dous países. A pregunta que un se formula é se a Pondal lle interesaba o sino dun país afastado no leste de Europa. En parte si, de certo, pola súa sensibilidade, formación en Santiago de Compostela nun período da axitación galeguista arredor do Mito dos Mártires de Carral, polas súas perspectivas amplísimas, polo seu interese pola historia, literatura, linguas estranxeiras e culturas foráneas (Ferreiro 1991: 17-19). A polaca non foi a única nación que apoiou Pondal na súa obra. Nos seus poemas aparecen referencias a Irlanda, Grecia, Serbia... mentres que "Bon cop de fals" é dedicado a Cataluña (Ferreiro 1999: 511-514). Porén, como o bardo nacional, ao final da súa vida, seguramente lle interesaba aínda máis o destino do seu propio pobo ao que lle dedicou a obra e a vida. Esta nación querida, que desde tanto tempo el e os seus compatriotas comprometidos tentaron espertar do letargo ${ }^{12}$, permanecía somnámbula.
Talvez non sería esaxerado afirmar que a sofrida Cincenta do poema pondaliano na realidade clama “¡Desperta Galicia!”.

Tanto máis que o paralelo entre Galicia e Polonia non encaixa por completo, nin sequera no que atinxe ao mito. A fama de Polonia debeuse precisamente á súa insumisión, obstinación e disposión constante á loita armada. Foron as sucesivas insurreccións, frustradas todas elas, que fixeron falar de Polonia en Europa, que espertaron as simpatías da opinión pública aínda dos Estados ocupantes, como foi o caso do Levantamento de Xaneiro na Alemaña, e que causaron a conseguinte emigración que divulgou o mito polaco por toda a Europa occidental. Polonia, así pois, non precisaba espertar. Estaba esperta todo o tempo. A que si o necesitaba era Galicia. E era o único, parece insinuar Pondal, que lle faltaba para recoller a súa gloria pasada.

\section{CONCLUSIÓNS}

A Polonia de “¡Desperta Polska!” responde perfectamente ao mito romántico e prestóuselle de forma idónea a Pondal para corroborar a propia visión de Galicia. O que o poeta galego recolle da realidade histórica dese país afastado é a súa hexemonía pasada e a súa combatividade actual. Pondal non se pregunta nin sobre o modelo concreto da democracia ou liberdade polacas nin sobre as causas da súa derrota. Non o ten que facer, porque o que lle interesa é a referencia a uns valores determinados que constitúen o núcleo da súa "contramitoloxía" de Galicia.

Pondal non quere que Galicia sexa asociada cunha nación sen Estado, cunha cultura minoritaria ou minorizada, cunha corrente rexional. Para Pondal a galega é unha nación a secas, sen adxectivos. O seu obxectivo non é a solidariedade coas outras nacións nunha

\footnotetext{
${ }^{12}$ A referencia ao sono de Galicia aparece non só na poesía de Pondal (“Os Pinos", “A lira de Tyrteo”), senón tamén nos seus contemporáneos como Francisco de la Iglesia ("A Galicia”) ou Murguía ("Los Precursores") así como nas épocas posteriores no poema "Longa noite de pedra" de Celso Emilio Ferreiro ou no cuadro de Castelao "Galicia duerme. Problema: Debe despertarse?”.
} 
situación parecida, non busca o apoio dos oprimidos. Aínda que as veces coinciden, as nacións que evoca Pondal son as que loitan pola súa liberdade, as que souberon facerse co seu destino coas súas propias mans. Cando Murguía (1975: 141) escribe nos "Precursores" sobre o seu amigo Eduardo, menciona a súa actitude fronte a esa "corriente moderna" do rexionalismo. "Los pueblos tienen los destinos que merecen, no os quejeis de vuestras desgracias: no pidais, exigid: ou honra, ou ferro" (Murguía 1975: 149).

Galicia clama a Polonia como un xigante a outro, durmido ou non, que ten o seu papel histórico de guiar as outras nacións. Deliberada ou casualmente, Pondal fai de Polonia o referente da loita pola independencia para todas as nacións oprimidas e obrígaa a exercer o liderado. Trátase desta hexemonía xenerosa da que falaba Cores Trasmonte (1957: 14-15) no caso galego. Así podemos explicar a presencia de Lajos Kossuth ${ }^{13}$ ou Taras Szewczenko (Cheochenko) ${ }^{14}$ como integrantes do mito polaco. A non ser que queiramos atribuíla á incultura do "más instruido de los poetas gallegos" (Ferreiro 1991: 18), nas palabras de Emilia Pardo Bazán.

Porén, Galicia clama sobre todo aos seus propios fillos. Con esa voz estrepitosa bérralles aos galegos que xa non quere ser Cincenta, non pensa sufrir máis; que xa é a hora de botar os farrapos e dispoñer as armas. Así como o fai desde hai máis dun século a nación irmá do Leste.

\section{REFERENCIAS BIBLIOGRÁFICAS}

Álvarez, Melquíades (1916): Intervención no Congreso dos Diputados, Diario de la Sesiones de Cortes 41, p. 1015.

Borges, Jorge Luis (1944): Tema del traidor y del héroe (dispoñíbel en: http://www.literatura. us/borges/tema.html).

Ceynowa, Florian (2004): Teksty więzienne. Wejherowo: Muzeum Piśmiennictwa i Muzyki Kaszubsko-Pomorskiej.

Cores Trasmonte, Baldomero (1957): “Ideario hegemónico de Pondal”, Lar 284-286, pp. 13-17.

FERnÁNDEZ PÉREZ-SANJulián, Carme (2009): "Narrativa e construción da identidade: «Os camiños da vida» de Ramón Otero Pedrayo", en L. Tato Fontaíña e M. do A. Tavares Maleval (org.), Estudos Galego-Brasileiros 3, pp. 137-151.

FERreiro, Manuel (1991): Do Dandysmo á Loucura: biografía e correspondencia. Santiago de Compostela: Laiovento.

(1999): "Terra verde, un poema inédito de Eduardo Pondal”, en R. Álvarez e D. Vilavedra (eds.), Cinguidos por unha arela común: homenaxe ó profesor Xesús Alonso Montero. Santiago de Compostela: Universidade, pp. 509-527.

(ed.) (2002): Poesía galega completa III: Poemas manuscritos. Santiago de Compostela: Sotelo Blanco.

(2007): De Breogán aos Pinos: o texto do Himno Galego. Santiago de Compostela: Laiovento.

GUS (2012): Wyniki Narodowego Spisu Powszechnego Ludności I Mieszkkań. Warszawa: GUS.

\footnotetext{
${ }^{13}$ Húngaro destacado durante a Primaveira dos Pobos que loitou contra a dependencia de Hungría do Imperio Austríaco.

${ }^{14}$ Este poeta ucraíno, de procedencia labrega, tamén representa a loita contra a Rusia zarista.
} 
HiLferding, Aleksander (1989): Resztki Stowian na południowym wybrzeżu morza Battyckiego. Gdańsk: Zrzeszenie Kaszubsko-Pomorskie.

Lama LóPez, María Xesús (2001): O celtismo e a materia de Bretaña na literatura galega: Cara á construcción dun contradiscurso histórico ficcional na obra de Xosé Luís Méndez Ferrín. Tese de doutoramento. Barcelona: Universitat (dispoñíbel en: http://www.tdx.cat/bitstream/ handle/10803/1739/02.MJLL_2de4.pdf? sequence=2).

MÉndez Ferrín, Xosé Luís (1990): De Pondal a Novoneyra. Vigo: Xerais.

Murguía, Manuel (1975): Los Precursores. A Coruña: La Voz de Galicia.

OBRACHT-PRONDZYŃSKI, Cezary (2003): Wkręgu problematyki kaszubsko-pomorskiej: studia $i$ szkice. Gdańsk-Wejherowo: Muzeum Piśmiennictwa i Muzyki Kaszubsko-Pomorskiej, Istytut Kaszubski.

Pondal, Eduardo (2002): Poesía galega completa III: Poemas manuscritos. Santiago de Compostela: Sotelo Blanco.

QueIzÁn, María Xosé (1986): "De florido poeta da raza a desflorador racista", A Nosa Terra Extra 7, pp. 55-58. 